\title{
A Numerical Study on Influent Flow Rate Variations in a Secondary Settling Tank
}

\author{
Junwei Su ${ }^{1} \mathbb{D}$, Le Wang ${ }^{2, *}$, Yumin Zhang ${ }^{2}$ and Zhaolin $\mathrm{Gu}^{1}$ \\ 1 School of Human Settlement and Civil Engineering, Xi'an Jiaotong University, Xi'an 710049, China; \\ sujunwei@mail.xjtu.edu.cn (J.S.); guzhaoln@mail.xjtu.edu.cn (Z.G.) \\ 2 Mechanical Engineering College, Xi'an Shiyou University, Xi'an 710065, China; zhangyumincorn@163.com \\ * Correspondence: lewang@my.swjtu.edu.cn
}

Received: 10 October 2019; Accepted: 21 November 2019; Published: 27 November 2019

\begin{abstract}
The secondary settling tank is an essential unit for the biochemical treatment of domestic sewage, and its operational effect influences the quality of effluent. Under the influence of the confluence of rainwater and sewage, wastewater use habits, etc., the inflow of the secondary sedimentation tank changes over time. In this paper, OpenFOAM, an open-source computational fluid dynamics package, was used to study the dynamic behaviors of solid-liquid two-phase flow in the tank under influent flow rate variations. A coupled method including a mixture model, drift equation and a dynamic boundary method is proposed. Numerical investigations were carried out for a $2 \mathrm{D}$ axisymmetric sedimentation tank using 12 cases. With increasing influent flow rate, sludge accumulates continuously in the bottom left side of the tank, sludge hopper, and inlet; the sludge blanket thickness near the right end of the tank increases continuously; and the sludge concentration in the tank approximately linearly increases with time, with a low slope. The developed framework is generic and is, therefore, expected to be applicable for modelling sludge sedimentation processes.
\end{abstract}

Keywords: secondary settling tank; numerical simulation; computational fluid dynamics; solid-liquid two-phase flow

\section{Introduction}

Secondary settling is referred to in the literature as "the most sensitive and complicated process in activated sludge plants" [1]. As an essential biological treatment unit in municipal wastewater treatment plants, the secondary settling tank (hereinafter called "the tank") restricts the wastewater treatment capacity [2,3]. The sludge sedimentation influences the quality of effluent. Therefore, it is important to study the sludge sedimentation law and its influencing factors in order to improve sludge sedimentation efficiency.

Some new methods have been used in studying sewage treatment systems, such as artificial neural networks [4,5], numerical simulation [6-8], and smoothed particle hydrodynamics [9]. In particular, numerical simulation technology has gradually become an important method used to study the sludge sedimentation mechanism and solid-liquid dynamical behavior in the tank [10-12]. Different numerical simulation techniques including the mixture model [13], the Navier-Stokes coupled sludge transport equation [10,14], and the Euler-Euler two-phase model [7], have been used to study sludge sedimentation. The results revealed the effects of the geometric structure, temperature distribution, settling velocity, and turbulence model on sludge sedimentation; further, the solid-liquid dynamics behavior and heterogeneous distribution of activated sludge concentration in the tank were discussed [6,8,15-18]. Gao and Stenstrom [19] adopted different turbulence models (standard $k-\varepsilon$, realizable $k-\varepsilon$, renormalization group $k-\varepsilon$ ) to model the dynamic behavior of solid-liquid in the tank. They found that different turbulence modes have little influence on the prediction of the suspended 
solids concentration at the outlet but a significant impact on the sludge blanket height. $\mathrm{Xu}$ et al. [7] developed a new force-based mechanical model in the Euler-Euler framework based on Newton's law rather than the flux theory and used the new model to describe the sludge settling process. They found that the predictions of this model were more accurate than those of flux theory-based models. Ramin et al. [13] developed a new settling velocity model, including hindered, transient, and compression settling, and showed that it could be calibrated to data from a simple, novel settling column experimental setup using the Bayesian optimization method differential evolution adaptive Metropolis (DREAM). In addition, correlations between the Herschel-Bulkley rheological model parameters and sludge concentration were identified with data from batch rheological experiments. Byonghi [11] studied the double perforated baffles in a rectangular secondary settling tank by numerical simulation. He found that the double perforated baffles could improve the quality of effluent water; when the flow rate was large, biological flocculation appeared in the front of the baffles, hindering the longitudinal movement of sludge in the tank. Gao and Stenstrom [20] studied the effects of baffling structures on buoyancy-induced turbulence flow in secondary settling tanks. The results showed that the effects of the secondary settling tank (SST) baffling structures on the buoyancy-induced turbulence can be divided into three zones: Zone A, where the baffling structures had negligible damping effects, and only the buoyancy-coupled turbulence model provided accurate predictions; Zone B, where the baffling structures partially dissipated the effect of buoyancy on turbulence, and the buoyancy-coupled model continued to provide accurate predictions but the buoyancy-decoupled turbulence model only provided qualitative but similar predictions; and Zone $C$, where the baffling structures fully dissipated the effect of buoyancy on turbulence, and both models provided similar, accurate predictions. Valle Medina and Laurent [6] focused on the development of a computational fluid dynamics (CFD) tool including not only the hydrodynamics of the settling tank but also recent advances in both hindered and compression settling modeling. Then, they studied the effects on the sludge blanket height and sludge concentration using the compression function. Gao and Stenstrom [21] investigated the effects of the buoyancy term $(\mathrm{Gb})$ in the turbulent kinetic energy (TKE) equation and two model parameters on the performance of secondary settling tanks. The results showed that the hydrodynamics can only be correctly predicted by a buoyancy-coupled TKE equation.

However, the above studies were usually based on steady conditions and seldom focused on sludge sedimentation behaviors in secondary settling tanks under influent flow rate variations. While affected by wastewater use habits, water consumption, confluence of rainwater and sewage, etc., the tank operates daily under unsteady operation conditions. Therefore, the flow rate of mixed liquid at the inlet of the secondary settling tank varies with time [22]. The dynamic influent flow rate of the mixed liquid at the inlet not only changes the velocity distribution in the tank but also correspondingly adjusts the turbulence energy and turbulent dissipation rate of the mixed liquid. Meanwhile, the convection and diffusion effect of the mixed liquid is changed. As a result, the sludge sedimentation in the tank is affected by the dynamic flow rate. Therefore, steady numerical results cannot possibly reveal the sludge sedimentation mechanism under dynamic conditions. It is very difficult to reproduce and predict the spatial and temporal evolution of the sludge distribution in the tank. Although it will not need more computational time to simulate the sludge settling process in the tank under dynamic influent flow, the boundary conditions need to consider the influence of time. This means that new boundary conditions need to be adopted.

This paper focuses on the liquid-solid dynamic behavior in the secondary settling tank under influent flow rate variations. Furthermore, the influence of reflux conditions is taken into account in the numerical simulation. Different from the previous numerical simulation studies on solid-liquid two-phase flow in a secondary settling tank under steady flow, this study reveals the sludge settling mechanism with respect to influent flow rate variations. The modeling result is expected to aid in the optimization of operating parameters of the tank. 


\section{Numerical Model}

OpenFOAM has been widely used in numerical simulations in multiphase hydrodynamic behavior research $[23,24]$. It has also been adopted as a platform to study the solid-liquid behavior in secondary settling tanks $[6,13,25]$.

\subsection{Mixture Model}

The mixture model is a commonly used mathematical model for the numerical simulation of secondary settling tanks, and it takes into account the two-phase slip velocities.

The mixture continuity equation is:

$$
\frac{\partial \rho_{m}}{\partial t}+\nabla \cdot\left(\rho_{m} v_{m}\right)=0
$$

where $\rho$ is density; $v$ is velocity; and the subscripts $m$ represent mixture. The mixture velocity is obtained as follows (Equation (2)):

$$
v_{m}=\frac{\alpha_{d} \rho_{d} v_{d}+\alpha_{w} \rho_{w} v_{w}}{\rho_{m}}
$$

where $\alpha$ is the volume fraction of the two phases; the subscripts $d$ and $w$ represent solid and liquid, respectively. There is a relationship between the liquid and solid volume fractions as shown in Equation (3); the mixture density is described in Equation (4).

$$
\begin{gathered}
\alpha_{d}+\alpha_{w}=1 \\
\rho_{m}=\alpha_{d} \rho_{d}+\alpha_{w} \rho_{w}
\end{gathered}
$$

The mixture momentum equation is expressed as:

$$
\frac{\partial \rho_{m} v_{m}}{\partial t}+\nabla \cdot\left(\rho_{m} v_{m} v_{m}\right)=-\nabla \cdot P_{m}+\nabla \cdot\left[\tau+\tau^{t}\right]-\nabla \cdot\left(\frac{\alpha_{d}}{1-\alpha_{d}} \frac{\rho_{d} \rho_{w}}{\rho_{m}} v_{s} v_{s}\right)+\rho_{m} g
$$

where $v_{s}$ is the sludge settling velocity and can be calculated via Equation (11); $\tau$ is the viscous stress tensor and is described by Equation (7); $\tau^{t}$ is the turbulent stress tensor; $g$ is gravitational acceleration; and $P_{m}$ is pressure.

The drift equation for the prediction of the solids distribution is:

$$
\frac{\partial \alpha_{d}}{\partial t}+\nabla \cdot\left(\alpha_{d} v_{m}\right)=-\nabla \cdot\left(\frac{\alpha_{d} \rho_{w}}{\rho_{m}} v_{s}\right)+\nabla \cdot \Gamma \nabla \alpha_{d}
$$

where $\Gamma$ is the diffusion coefficient.

The standard $k-\varepsilon$ turbulence equation was used to consider turbulent effects $[25,26]$.

\subsection{Rheological Model}

The Herschel-Bulkley model is used to describe the shear stress [13,27-29], as shown below:

$$
\tau=\tau_{0}+K \gamma^{n}
$$

where $\tau_{0}$ is the yield stress and can be calculated via Equation (8); $K$ is the viscosity coefficient and is expressed as Equation (9); $n$ is the rheological index and is described by Equation (10); and $\gamma$ is the shear rate. However, the sludge concentration distribution in the tank is not uniform. The rheological properties of the mixed liquid in the tank are related to the concentration. According to Ramin's study, an activated sludge sample was collected from the combined recycle flow channel of 
the Lundtofte wastewater treatment plant on the day of the settling experiments. Sludge samples taken were aerated overnight with coarse air bubbles and the sampled effluent SST was stored at $4{ }^{\circ} \mathrm{C}$ for the rheological experiments conducted on the following day. The three parameters $\left(\tau_{0}, K, n\right)$ were estimated by fitting the Herschel-Bulkley model to the rheological measurements at the shear rates between 0.01 and $250 \mathrm{~s}^{-1}$ [13]. The parameters of different sludge concentrations $(5,7.1,8.5$, $10,12.8 \mathrm{~kg} / \mathrm{m}^{3}$ ) were investigated in a simple laboratory set-up, consisting of a glass column with a Solitax ${ }^{\circledR}$ total suspended solids sensors [13]. In order to further study the real rheological properties of the mixed liquid, according to the reference by Ramin et al. [13], the following formulae were obtained by fitting the shear stress formula with the concentration in this paper:

$$
\begin{gathered}
\tau_{0}=A X^{B} \\
K=\mu_{W} \exp (C \times X) \\
n=\frac{1}{1+D \times X^{E}}
\end{gathered}
$$

where $A$ is $0.00066 \mathrm{~kg}^{(1-B)} \mathrm{m}^{(3 B-1)} \mathrm{s}^{-2} ; B$ is a constant, $2.18 ; C$ is $0.28 \mathrm{~m}^{3} / \mathrm{kg} ; D$ is $0.00083 \mathrm{~m}^{3 E} \mathrm{~kg}^{-E} ; E$ is a constant, 2.57; $X$ is the sludge concentration; and $\mu_{w}$ is the viscosity coefficient of water.

\subsection{Settling Velocity}

The hindered settling velocity model by Takacs et al. [30] was used in the numerical simulation. It is also commonly adopted as the settling velocity model to investigate sludge sedimentation in the tank [22,31]. Further, a series of batch settling tests were performed using the sludge samples diluted with secondary settling tank effluent over a concentration range of $1.7-5.1 \mathrm{~kg} / \mathrm{m}^{3}$, which is typical for feed concentration into secondary settling tanks [13]. Then, the measurement parameters for the sludge rheological properties and settling velocity were analyzed. The formula is as follows:

$$
v_{s}=v_{0} e^{-r_{H} \cdot X}-v_{0} e^{-r_{p} \cdot X}
$$

where $X$ is the sludge concentration at different locations in the tank; $X_{0}$ is the initial sludge concentration at the inlet; and $r_{H}$ and $r_{p}$ are 0.42 and 4.2 , respectively.

\section{Model Setting and Verification}

\subsection{Physical Model}

Figure 1 shows the geometrical structure and mesh of the 2D axisymmetric circular sedimentation tank which was used to study dynamic behaviors of solid-liquid two-phase flow in references [32,33]. The secondary settling tank studied is located in Lundtofte wastewater treatment plant (Lyngby, Denmark). It is a circular center-feed conical tank [13]. As shown in Figure 1a, the tank has a length of $12.25 \mathrm{~m}$, height of $6.2 \mathrm{~m}$, inlet width of $0.225 \mathrm{~m}$, outlet width of $0.08 \mathrm{~m}$, and reflux outlet width of $0.58 \mathrm{~m}$. In order to express the material balance in the tank more clearly, it is assumed that the flow rate of the mixed liquid at the inlet is $Q_{i n}$; the sludge concentration at the inlet is $X_{\text {in }}$; the flow rate at the outlet is $Q_{\text {out }}$; the sludge concentration at the outlet is $X_{\text {out }}$; the flow rate at the reflux outlet is $R^{*} Q_{\text {out }}$, which is related to the flow rate at the outlet; and the sludge concentration at the reflux outlet is $X_{\text {rec }}$. Further, $Q_{\text {in }}=Q_{\text {out }}+R^{*} Q_{\text {out }}$.

Figure $1 \mathrm{~b}$ shows the unstructured mesh of the whole computational domain. As shown in Figure $1 \mathrm{~b}$, the mesh is denser around the inlet area, sludge hopper, and outlet. The minimum face area is $0.0002597 \mathrm{~m}^{2}$, and the maximum face area is $0.0659 \mathrm{~m}^{2}$. In this paper, a grid independence study was performed to ensure the results of independent mesh resolution. The total number of cells in the numerical simulation is 7088 . 

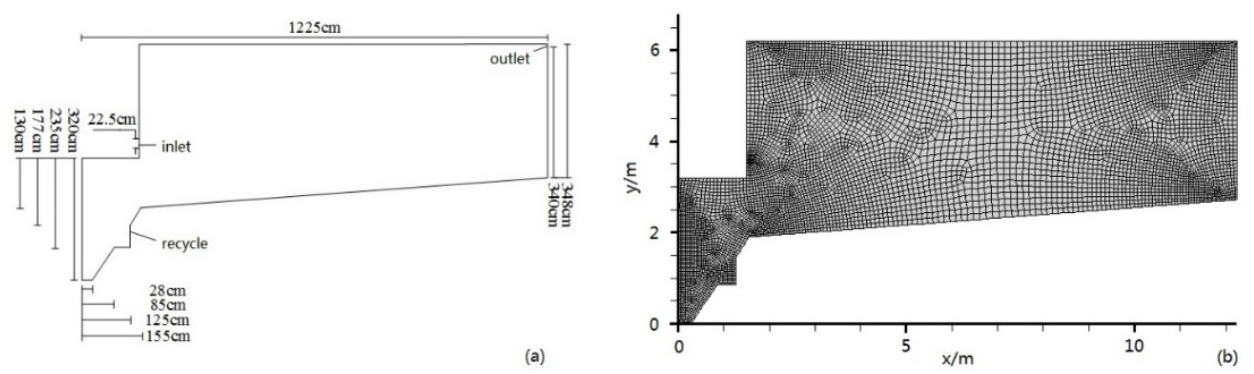

Figure 1. Physical mode and mesh: (a) geometry of the secondary sedimentation tank; (b) grid. "Reproduced with permission from [Su, J.W.; Wang, L.; Liu, Y.J.], [Two-Phase flow numerical simulation of secondary settling tank and influence of mixed liquor rheological properties], published by [Tech. Water Treat. (in Chinese)], [2019]; [Su, J.W.; Wang, L.; Gu, Z.L.; Chen, J.], [Numerical simulation of solid/ non-Newtonian liquid two-phase flow in the secondary sedimentation tanks with different inlet flow rates], published by [Chin. J. Appl. Mech. (in Chinese)], [2019]."

\subsection{Parameter Setting}

The chosen parameter values were as follows: water density, $1000 \mathrm{~kg} / \mathrm{m}^{3}$; sludge density, $1600 \mathrm{~kg} / \mathrm{m}^{3}$; gravity acceleration, $9.8 \mathrm{~m} / \mathrm{s}^{2}$; flow rate at the inlet, $242 \mathrm{~m}^{3} / \mathrm{h}$; and $\mathrm{R}, 1.42$. The PIMPLE algorithm was adopted to decouple velocity and pressure. In the numerical simulation, at a time step, the correct number was 4 . The relaxation factor of each physical variable was set to 0.7 .

\subsection{Case Setting}

It was assumed that the increase of the influent flow rate is linear and that the sludge concentration at the inlet does not change with time. All the cases were modeled for $1800 \mathrm{~s}$ under steady conditions (with flow rate at the inlet of $242 \mathrm{~m}^{3} / \mathrm{h}$ and flow rate at the outlet of $100 \mathrm{~m}^{3} / \mathrm{h}$ ). As a result, we obtained relatively stable solid-liquid dynamic behavior in the tank. Then, five different cases were used to model the sludge sedimentation under different influent flow rates from 1.5 to 4 during the time from 1800 to $5400 \mathrm{~s}$. At each time step, a program was added to alter the influent flow in a mandatory way to the one at the next time point. This ensured that the influent flow rate increased linearly with time. In addition, the dynamic reflux ratio is also discussed for the cases. The relevant settings for the cases are shown in Table 1.

Table 1. Case settings.

\begin{tabular}{|c|c|c|c|c|c|c|c|c|c|c|c|c|}
\hline $\begin{array}{l}\text { Case Number } \\
\text { Parameter }\end{array}$ & 1 & 2 & 3 & 4 & 5 & 6 & 7 & 8 & 9 & 10 & 11 & 12 \\
\hline $\begin{array}{l}\text { Influent flow rate from } 0 \text { to } \\
1800 \mathrm{~s}\left(\mathrm{~m}^{3} / \mathrm{h}\right)\end{array}$ & 242 & 242 & 242 & 242 & 242 & 322.7 & 242 & 242 & 242 & 242 & 242 & 242 \\
\hline $\begin{array}{l}\text { Influent flow rate from } 1800 \\
\text { to } 5400 \mathrm{~s}\left(\mathrm{~m}^{3} / \mathrm{h}\right)\end{array}$ & 363 & 484 & 605 & 726 & 968 & 322.7 & 242 & 363 & 484 & 605 & 726 & 968 \\
\hline $\begin{array}{l}\text { Outlet flow rate from } 0 \text { to } \\
1800 \mathrm{~s}\left(\mathrm{~m}^{3} / \mathrm{h}\right)\end{array}$ & 100 & 100 & 100 & 100 & 100 & 133.3 & 100 & 100 & 100 & 100 & 100 & 100 \\
\hline $\begin{array}{l}\text { Outlet flow rate from } 1800 \text { to } \\
5400 \mathrm{~s}\left(\mathrm{~m}^{3} / \mathrm{h}\right)\end{array}$ & 150 & 200 & 250 & 300 & 400 & 133.3 & 100 & 100 & 100 & 100 & 100 & 100 \\
\hline Influent flow rate multiple & 1.5 & 2 & 2.5 & 3 & 4 & - & - & 1.5 & 2 & 2.5 & 3 & 4 \\
\hline $\begin{array}{l}\text { Influent sludge concentration } \\
(\mathrm{g} / \mathrm{L})[13]\end{array}$ & \multicolumn{12}{|c|}{2.1} \\
\hline Reflux value & \multicolumn{12}{|c|}{1.42} \\
\hline
\end{tabular}

\subsection{Verification}

\subsubsection{Ideal Sedimentation Tank}

The solid-liquid behavior was simulated in an ideal sedimentation tank in order to verify the accuracy of the above numerical method and numerical model. The ideal sedimentation tank has 
a length of $8.65 \mathrm{~m}$, width of $1 \mathrm{~m}$, inlet width of $1 \mathrm{~m}$, outlet width of $0.1 \mathrm{~m}$, velocity at the inlet of $0.0191 \mathrm{~m} / \mathrm{s}$, and solid volume fraction of 0.001 . Brennan described the facilities, methods, and steps of the experiment in detail [25,34]. According to Dahl's study [25], measurements of velocity and dispersed phase concentration were taken along the center plane of the test section at distances of $3.0 \mathrm{~m}, 5.0 \mathrm{~m}$ and $7.0 \mathrm{~m}$ from the inlet end wall. Integration of the velocity profiles to give the volumetric flux through each station at the experimentally recorded times shows variation from the claimed influent volume. The mixture velocity was measured by an electro-magnetic induction sensor and the suspended sludge concentration was measured by an optical turbidity meter. Figure 2a shows the structured meshing of the ideal sedimentation tank. The flow rate and solid volume fraction at different locations in the ideal sedimentation tank were given. Figure $2 \mathrm{~b}$ shows a comparison of the mixture (i.e., mixture of sludge and water) velocity at $3 \mathrm{~m}, 5 \mathrm{~m}$, and $7 \mathrm{~m}$ in the $x$ direction. As shown in Figure $2 \mathrm{~b}$, it was found that the mixture velocity was high in the middle of the tank and low at both sides of the tank. The simulated mixture velocity value agreed well with the experimental value.

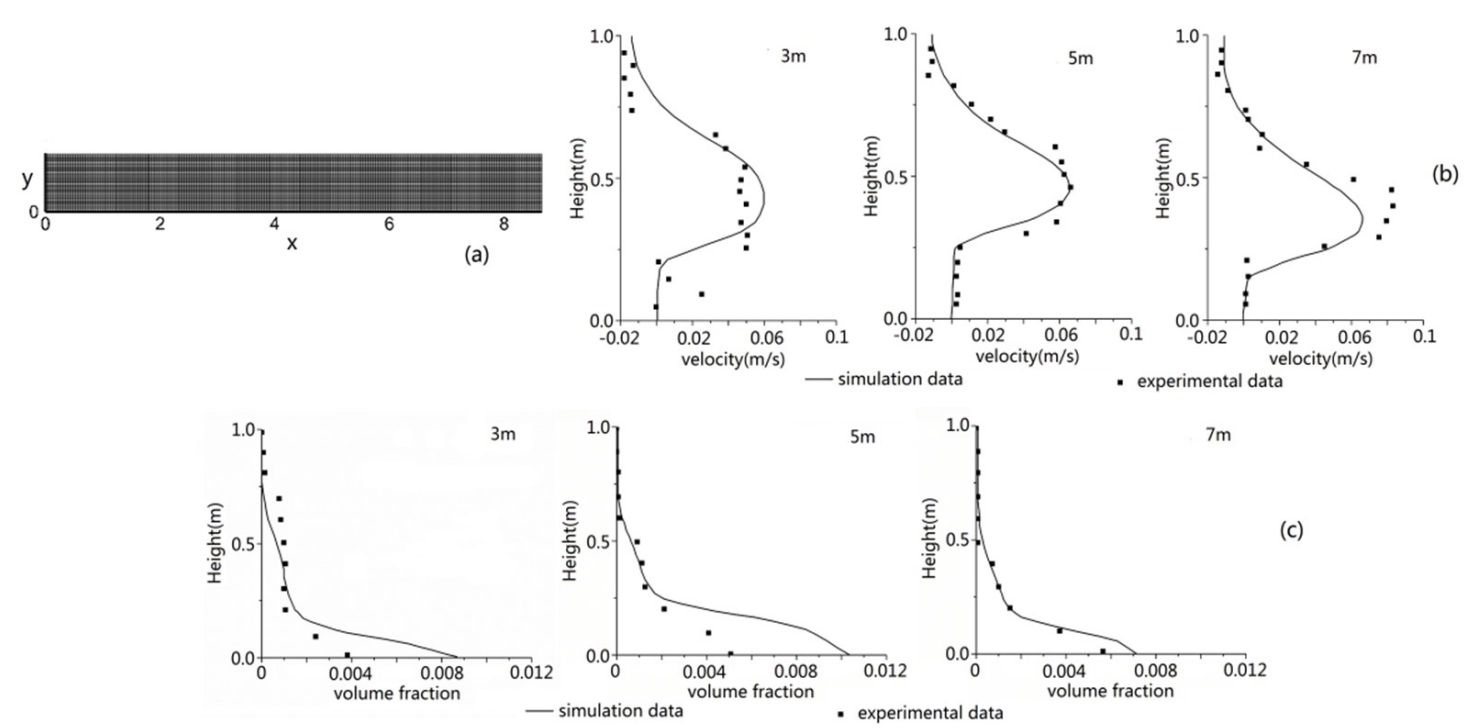

Figure 2. Verification of the velocity and volume fraction: (a) mesh; (b) verification of velocity; (c) verification of volume fraction.

Figure $2 \mathrm{c}$ shows the experimental and numerical predicted volume fraction at $3 \mathrm{~m}, 5 \mathrm{~m}$, and $7 \mathrm{~m}$ in the $x$ direction. It was found that the simulated values and experimental values agreed well on the results in the upper and middle part of the tank. The simulated volume fraction values at the bottom of the tank were higher than the experimental values at $3 \mathrm{~m}$ and $5 \mathrm{~m}$ in the $x$ direction. The reason for this may be that the settling and physical parameters of the sludge were chosen from experience and, thus, the simulated result may overestimate the sludge concentration near the bottom of the tank.

\subsubsection{Dynamic Flow Verification}

The influent flow rates of Cases 1-7 were investigated and compared with the analytical values of the flow rate designed in different cases at 2400 s, 3000 s, 3600 s, 4200 s, and 4800 s. It can be seen in Figure 3 that the influent flow rate variations with time were identical to the analytical values at different times, which proves that the algorithm of the boundary conditions guarantees dynamic change of the flow rate at the inlet with time. 


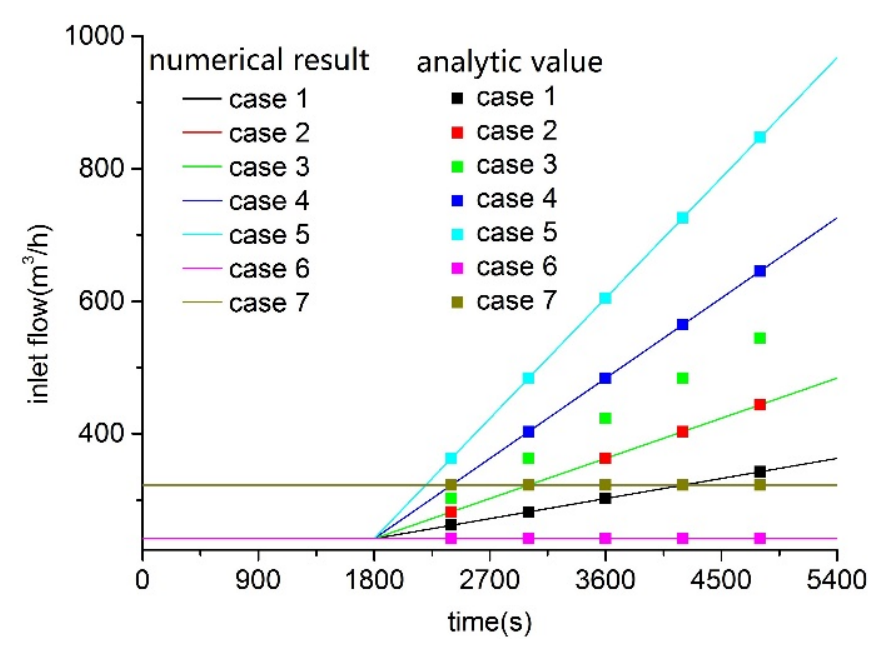

Figure 3. Comparison of numerical simulated and analytical influent flow rates.

\section{Results and Discussion}

\subsection{Streamline}

Figure 4 shows the streamline in different cases in the tank at $5400 \mathrm{~s}$. Generally speaking, the sludge settling effect proceeds well when the length of the recirculation zone in the secondary sedimentation tank is long [35]. The actual flow field in the tank has complicated structures, usually three-layer vortex structures, which is consistent with the findings of Van and Kranenburg [36] during monitoring of the flow field in an actual secondary settling tank. The reason for this may be that the different sludge concentrations show different rheological properties at different depths in the tank. The upper-layer vortex mainly influences the clarification area above the sludge blanket; the middle-layer vortex affects the flow pattern of the mixture in the middle and lower parts of the tank; and the lower-layer vortex affects the flow pattern of the mixture at the bottom of the tank. In the upper and middle parts of the sludge hopper, there is a main control vortex which affects the flow of the mixture in most areas of the sludge hopper. A small vortex distributes at the bottom of the sludge hopper, which restricts the transport of the sludge from the bottom to the middle part of the sludge hopper. As shown in Figure 4a-e, comparing Cases 1-5, both the number and shape of the vortices in the upper part of the tank change significantly, and those in the middle and lower parts of the tank change insignificantly. Moreover, the flow of the mixture is still controlled by a narrow and long vortex in the lower part of the tank. In Figure 4f,g, when the influent flow rate remains unchanged, there is little difference in the vortex structure in the tank, i.e., a certain difference in the vortex-affected area extending only between the upper right side and the middle and lower parts of the tank. As can be seen from Figure $4 \mathrm{~h}, \mathrm{i}$, the effluent flow rate does not change with time, and only the influent flow rate changes with time. From Cases $8-12$, it is found that the distribution and number of vortex structures in the tank are different in the upper part of the tank; the flow of the mixture is still controlled by a narrow and long vortex in the middle and lower parts of the tank. 

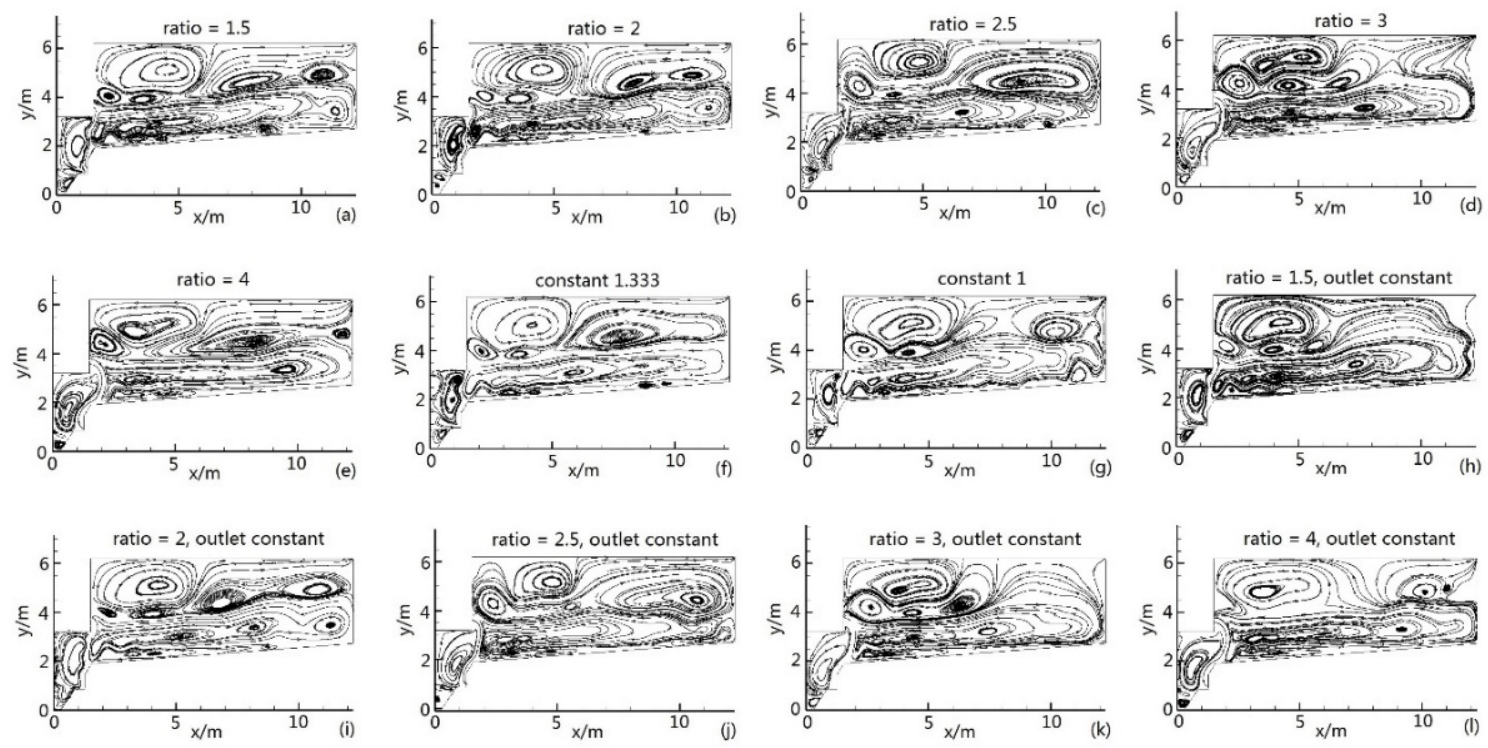

Figure 4. Streamline of the secondary sedimentation tank: (a) Case 1; (b) Case 2; (c) Case 3; (d) Case 4; (e) Case 5; (f) Case 6; (g) Case 7; (h) Case 8; (i) Case 9; (j) Case 10; (k) Case 11; and (1) Case 12.

\subsection{Sludge Concentration Distribution}

Figure 5 shows the sludge concentration distributions in the tank at $5400 \mathrm{~s}$ in different cases. The sludge concentration in the upper part of the tank was very low. With increasing depth in the tank, the sludge concentration increased continuously and reached a peak at the bottom of the sludge hopper. As shown in Figure 5a-e, comparing Cases 1-5, as the influent flow rate increased from 1.5 to 4 , the distribution area of sludge concentration of $>1.12 \mathrm{~g} / \mathrm{L}$ widened around the inlet (Block 1 area). Kim et al. [37] hypothesized that the density effect was caused by increased sludge concentration inlet loading on the overall flow field. The sludge constantly accumulated, and the sludge concentration constantly increased at the bottom left side of the tank (Block 2 area), while the sludge blanket constantly thickened near the right side of the tank (Block 3 area); in addition, the distribution area of high sludge concentration $(>8.87 \mathrm{~g} / \mathrm{L})$ increased at the bottom of the sludge hopper (Block 4 area). This was caused by the following factors: (1) when the mixture flowed into the tank, the sludge particles gradually settled down due to gravity and accumulate. Then, the gap between sludge particles gradually decreased. Consequently, the sludge concentration increased in the tank. (2) Increase in the influent flow rate led to an increase in the total sludge quantity in the whole tank; little sludge was discharged through the outlet, most of the sludge settled in the sludge hopper, and part of the sludge was discharged through the reflux outlet. As a result, the sludge concentration increased and the sludge accumulated continuously in the sludge hopper area. (3) Due to the high viscosity of sludge, the mixture had poor fluidity leading to easier sludge settlement at the bottom of the tank. (4) The flow dead-zone affected the mixture flow at the bottom of the sludge hopper and tank. Therefore, the sludge concentration increased in these areas.

As shown in Figure $5 \mathrm{f}, \mathrm{g}$, the steady flow rate at the inlet in Case $6\left(322.7 \mathrm{~m}^{3} / \mathrm{h}\right)$ was higher than that in Case $7\left(242 \mathrm{~m}^{3} / \mathrm{h}\right)$. Additionally, under steady inflow, the results of Case 6 were consistent with the result by Guyonvarch et al. [27]. Consequently, the sludge concentration in the bottom right side of the tank increased significantly. Cases 7 and 8 showed significantly broader sludge concentration distributions at the bottom of the sludge hopper (sludge concentration $>8.87 \mathrm{~g} / \mathrm{L}$ ) than did Cases 1-5. The reason for this may be that the vortex is more stable under steady flow. Thus, it was conducive to sludge sedimentation. As shown in Figure 5h,i, the sludge distribution in Cases 8-12 was similar to that in Cases 1-5; Cases 8-12 showed slightly higher sludge concentration around the bottom right side than did Cases 1-5 if the change in the reflux (Cases 8-12) was not considered. This may be due to larger sludge discharge from the reflux outlet in Cases 8-12 than in Cases 1-5 and, thus, lower 
total sludge quantity in the whole tank. For a quantitative analysis of the average spatial sludge concentration in the tank, see Figure 6.
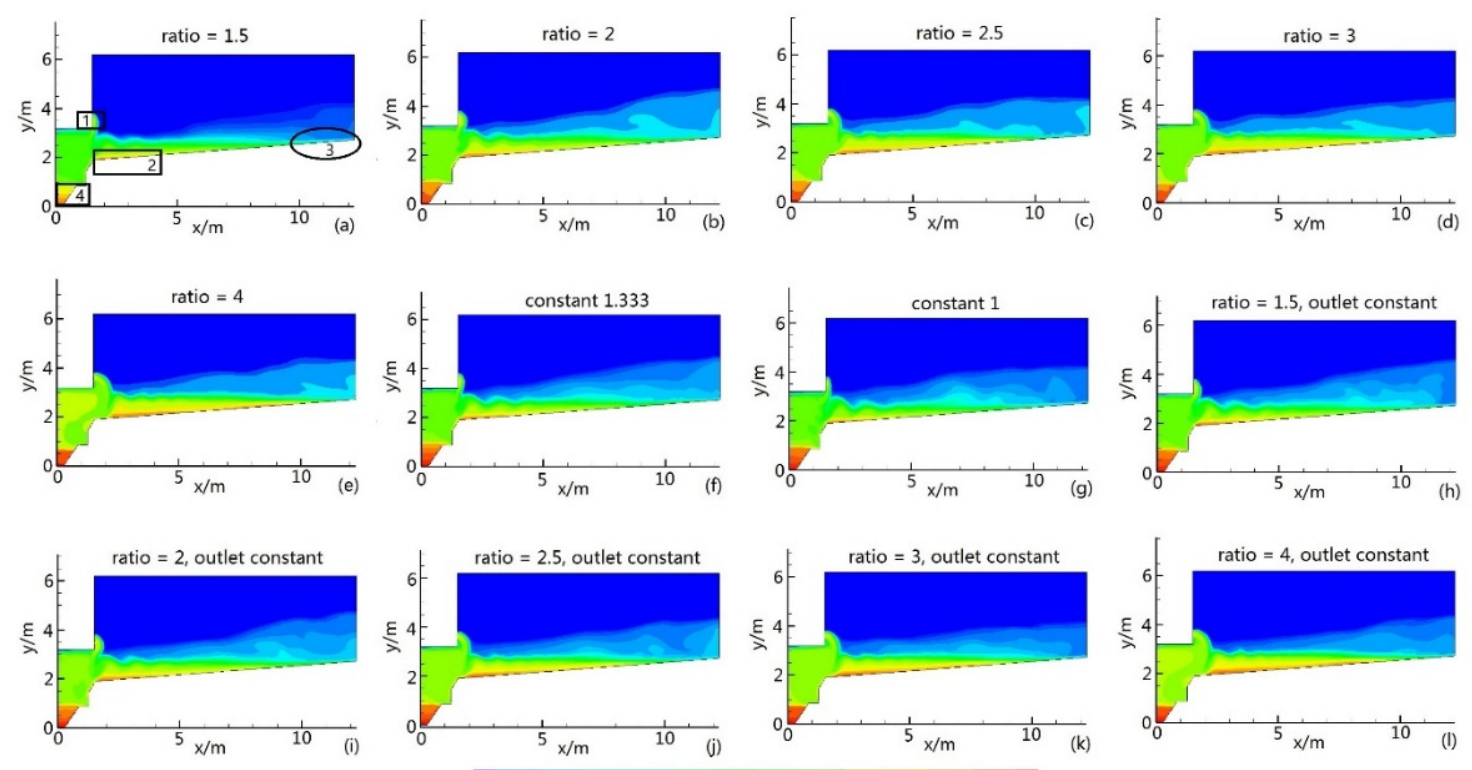

5.00E-02 1.41E-01 3.97E-01 1.12E+00 3.15E+00 8.87E+00 2.50E+01

Figure 5. Distributions of the sludge concentration $(\mathrm{g} / \mathrm{L})$ under different cases: (a) Case 1; (b) Case 2; (c) Case 3; (d) Case 4; (e) Case 5; (f) Case 6; (g) Case 7; (h) Case 8; (i) Case 9; (j) Case 10; (k) Case 11; (l) Case 12.
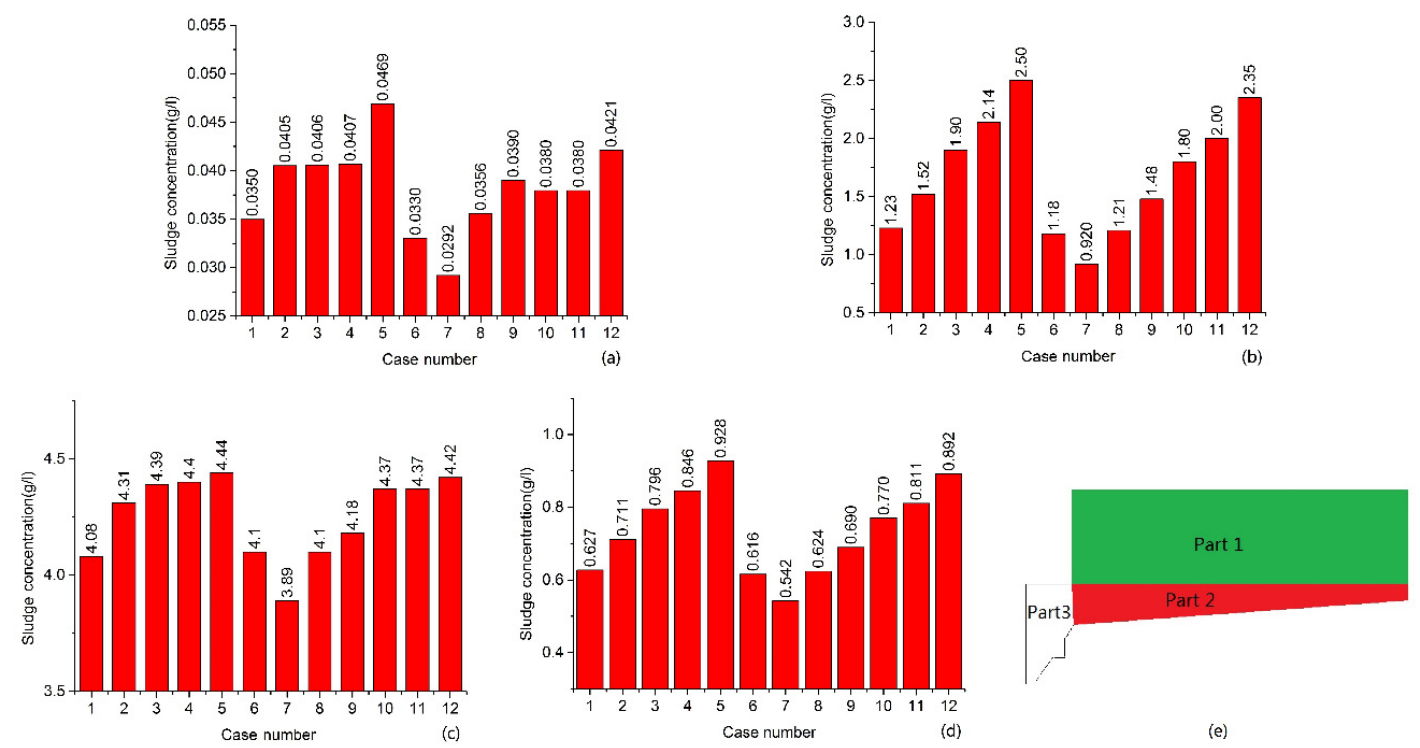

Figure 6. The average sludge concentrations of different zones: (a) Part 1; (b) Part 2; (c) Part 3; (d) the whole; (e) subarea.

Figure 6 shows the average spatial sludge concentrations in different parts of the tank. As shown in Figure 6e, the tank can be divided into three parts-the upper part called Zone 1, the bottom called Zone 2, and the sludge hopper area called Zone 3. As shown in Figure 6a, the different cases all had lower average sludge concentration in Zone 1 than in the other zones. Among them, Case 7 had the lowest average sludge concentration in Zone 1; Cases 2-4 and Cases 9-11 had similar sludge concentration values. However, Cases 5 and 12 had much higher sludge concentrations than the other cases. As can be seen from Figure 6b, different cases had higher average sludge concentrations in Zone 
2 than the cases for Zone 1; the average sludge concentrations in Cases 1-5 and 8-12 increased with increasing influent flow rate. It was found by comparing Cases 1 and 8, Cases 2 and 9, Cases 3 and 10, Cases 4 and 11, and Cases 5 and 12 that the dynamic change settings of the flow rate at the reflux outlet did not significantly influence the sludge concentration in Zone 2 and only slightly reduced the average sludge concentration. As shown in Figure $6 c$, in Zone 3, different cases had the biggest average sludge concentrations in the tank. The fluctuation of sludge concentration in the different cases was smaller in Zone 3 than in other zones. As shown in Figure 6d, the average sludge in the whole tank was a bit higher in Cases 1-5 than that in Cases 8-12. The changes in the sludge concentration in Zone 2 and Zone 3 were similar in different cases. However, the sludge concentration in Zone 3 was lower than that in Zone 2 in different cases. In summary, the sludge concentration in Zone 2 greatly influenced the average sludge concentration in the tank, and the dynamic change settings of the flow rate at the reflux outlet influenced the average sludge concentration in the tank very little.

Figure 7 shows the change in the average spatial sludge concentration in the tank with time. As shown in Figure 7a-c, the sludge concentration in the tank in Cases 1-12 approximately linearly increased with time, with low slope. Among them, Case 5 had the highest average spatial sludge concentration over time, followed by Case 12 . The average sludge concentration in the tank was mainly determined by the sludge input, not the dynamic reflux. A comparison of Cases 5 and 1 at $5400 \mathrm{~s}$ indicated that the average sludge concentration in Case 5 was 1.47 times that in Case 1. However, the influent flow rate in Case 5 was 2.67 times that in Case 1. That means that much more sludge was discharged through the reflux outlet in Case 5.
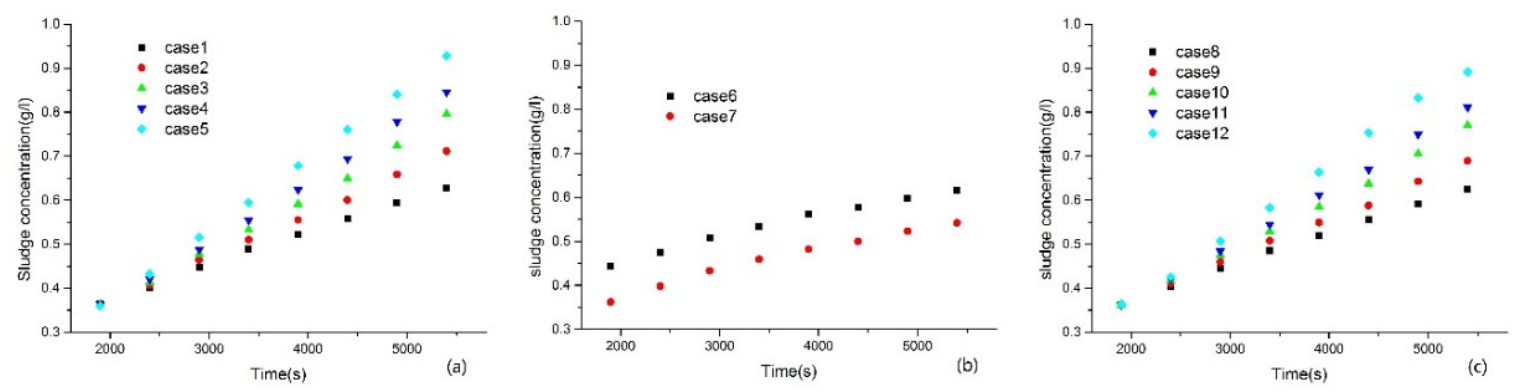

Figure 7. The average sludge concentration in the secondary tank at different times: (a) Cases 1-5; (b) Cases 6 and 7; (c) Cases 8-12.

Figure 8 shows the sludge concentrations at different time points at the monitoring sites $(10 \mathrm{~m}$, $3 \mathrm{~m}$ ) in the bottom right side of the tank. As shown in Figure 8a, the sludge concentrations in Cases 1-5 increased in a fluctuant manner with time. This is mainly because (1) the flow field of the mixture in the tank remained in a non-steady state and (2) the monitoring site had low sludge concentrations, leading to easy convection and diffusion of the sludge. However, the increase of the influent flow rate with time caused the sludge concentration to increase in this area.
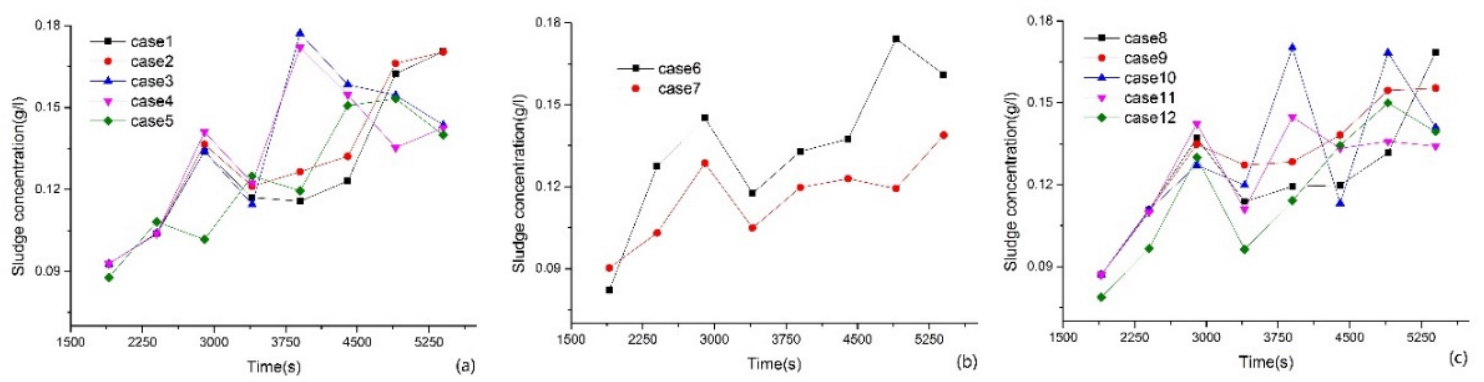

Figure 8. The sludge concentrations at the observation points $(10 \mathrm{~m}, 3 \mathrm{~m})$ at different times: (a) Cases 1-5; (b) Cases 6 and 7; (c) Cases 8-12. 
In Figure $8 \mathrm{~b}$, the sludge concentrations at the monitoring point increased in a fluctuant manner with time in Cases 6 and 7. Besides this, the sludge concentrations in Case 6 were higher than those in Case 7 at 2400 s, 2900 s, 3400 s, 3900 s, 4400 s, 4900 s, and 5400 s. This is because the steady-state flow rate at the inlet in Case 6 was larger than that in Case 7. As shown in Figure 8c, Cases 8-12 were different in terms of their sludge concentrations at varying time from Cases $1-5$, which means that the change in the reflux flow rate influenced the instantaneous sludge concentration in the tank.

\subsection{Velocity Distribution}

Figure 9 shows the velocity distributions in the tank in different cases. The fluid flow behaviors were very complicated in the tank. Among the 12 different cases, the upper part of the tank had lower velocity; the velocity in the lower part was higher than that in the middle part, and the high velocity area $(>0.0549 \mathrm{~m} / \mathrm{s})$ was distributed from the inlet to the reflux outlet. This is mainly because (1) the mixture at the inlet flowed downwards due to the viscous effect of the fluid and gravity induced sedimentation of sludge in the tank, and (2) one stream of the mixed liquid flowed directly to the reflux outlet along the sludge hopper due to the special geometric structure of the area above the sludge hopper; thus, insufficient attenuation of the flow velocity leaded to larger velocity in the area. Due to the larger velocity distributed in the sludge hopper area, the mixture directly flowed out without complete sedimentation. Therefore, it was not conducive to the efficient utilization of the tank. In addition, the velocity between the middle and lower parts of the tank was low in different cases, which was beneficial for sludge sedimentation in this area.
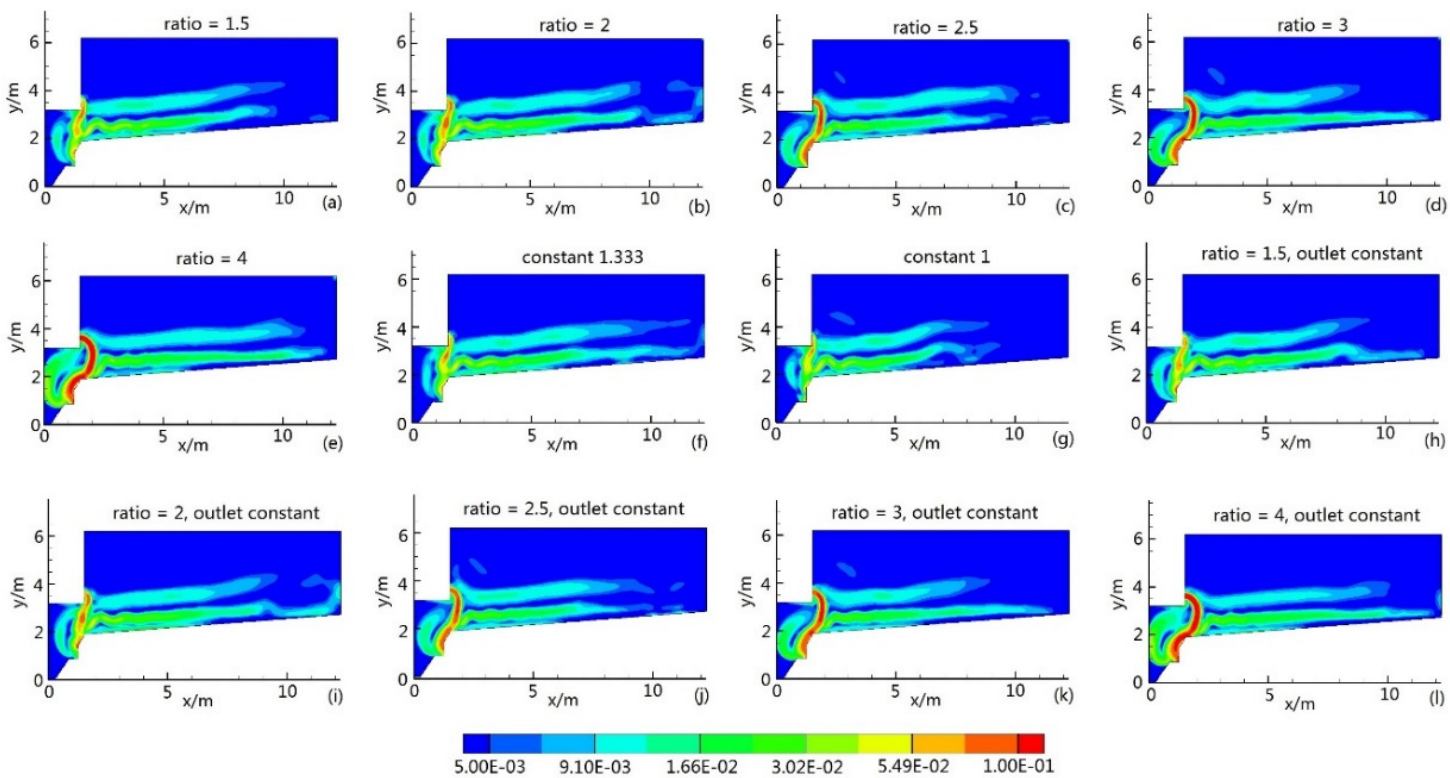

Figure 9. Distribution of velocity magnitude under different cases: (a) Case 1; (b) Case 2; (c) Case 3; (d) Case 4; (e) Case 5; (f) Case 6; (g) Case 7; (h) Case 8; (i) Case 9; (j) Case 10; (k) Case 11; (l) Case 12.

As shown in Figure 9a-e, comparing Cases 1-5, with increasing influent flow rate, the area with velocity of over $0.0166 \mathrm{~m} / \mathrm{s}$ expanded at the bottom of the tank. In particular, an obvious S-shaped velocity $(>0.0166 \mathrm{~m} / \mathrm{s})$ distribution formed between the inlet and reflux outlet. In addition, with increasing influent flow rate, the high velocity area $(>0.0166 \mathrm{~m} / \mathrm{s})$ was distributed in the right wall area of the tank. As a result, the liquid entrained sludge and moved to the upper outlet, which was not beneficial for sludge settlement in the area. As shown in Figure 9f,g, the velocity at the bottom and middle of the tank in Case 6 was larger than that in Case 7. In Figure 9h,i, Cases 8-12 showed similar velocity distributions to Cases $1-5$. The dynamic change of the flow rate at the reflux outlet had little impact on the velocity distribution. 
Figure 10 shows the average spatial velocities of different cases in different zones. The average spatial velocities in Cases 5 and 12 were similar but higher than those in other cases. The average velocity in Zone 1 was larger than that in other zones. That is because the sludge concentration in Zone 1 is low and the mixture is very flowable. The average velocity in Zone 3 was lower than that in other zones. The reason for this is that high sludge concentration causes a decrease in the fluidity of the mixture. As shown in Figure 10a, with increasing influent flow rate, the average velocity in the different cases increased in Zone 1, especially in Cases 5 and 12. As can be seen from Figure 10b, the average velocity increased with increasing influent flow rate. As shown in Figure 10c, the average velocity in Cases 1-5 increased more than that in Cases 8-12 because the sludge concentration in Cases 8-12 was high. As shown in Figure 10d, the average velocity in the different cases was much lower in the whole area than in Zones 1 and 2 but higher than in Zone 3.
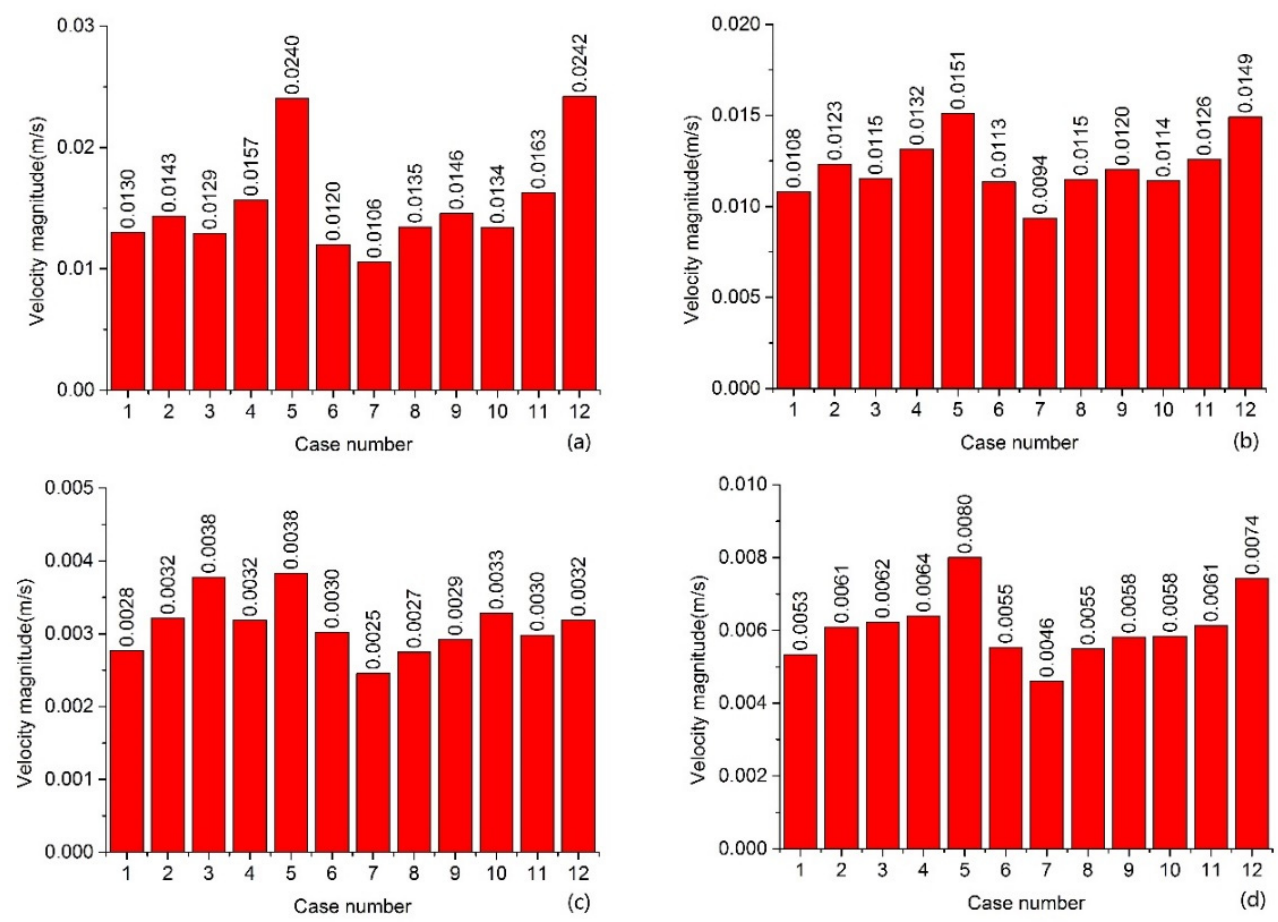

Figure 10. The velocity magnitude of different zones: (a) Part 1; (b) Part 2; (c) Part 3; (d) the whole.

Figure 11 gives the changes in velocity at the monitoring sites $(10 \mathrm{~m}, 3 \mathrm{~m})$ with time. As shown in Figure 11a, the velocity at the monitoring sites was between 0 and $0.012 \mathrm{~m} / \mathrm{s}$ and fluctuated with time in Cases 1-5. As shown in Figure 11b, although Case 6 had a much bigger influent flow rate than Case 7, the velocities at 2400 s, 2900 s, 4900 s, and 5400 s were relatively low. As shown in Figure 11c, similar to Cases 1-5, the velocity in Cases 8-12 decreased first, then increased, and finally decreased again. Because the sludge constantly settles down, the flow characteristics of the mixture changed accordingly.
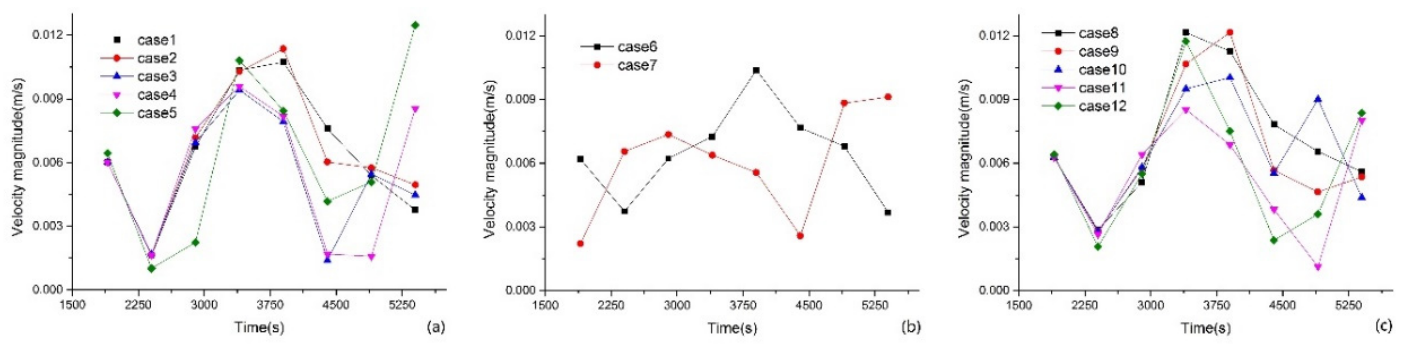

Figure 11. The velocity magnitude at the observation points $(10 \mathrm{~m}, 3 \mathrm{~m})$ at different times: (a) Cases 1-5; (b) Cases 6 and 7; (c) Cases 8-12. 


\subsection{Sludge Settling Velocity Distribution}

In order to reveal the different sludge concentration distributions in different cases, the sludge settling velocities at different flow rates are shown in Figure 12. Low sludge settling velocity $(>-0.0003 \mathrm{~m} / \mathrm{s})$ was distributed in the upper part of the tank and close to the bottom of the tank and the bottom of the sludge hopper; the sludge settling velocity was higher in the bottom and middle parts of the tank. Ramin et al. [13] also found the same research phenomenon in their simulations. From the hindered settling velocity model by Takacs et al. [30], we can explain the result: (1) the sludge concentration was very low, and the sludge was suspended in the upper part of the tank; (2) the type of sludge settling was flocculent or free settling in the bottom and middle parts of the tank, so the sludge settling velocity was higher. As shown in Figure 12a-e, in Cases 1-5, low sludge settling velocity $(>-0.0003 \mathrm{~m} / \mathrm{s})$ was mainly distributed in the upper part and bottom of the tank, as well as in the bottom of the sludge hopper. The sludge settling velocity in the upper part of the tank was lowest because of the minimal sludge concentration and sludge suspension in this area. However, as the sludge settled down in the bottom of the tank and sludge hopper area, the gap between sludge particles continuously decreased; thus, the sludge possibly settled down under gravity at a higher rate. It was found by comparing Cases $1-5$ that the settling velocity in the middle and upper parts of the sludge hopper decreased continuously, meaning that incomplete sludge sedimentation in the sludge hopper area led to a higher sludge concentration value at the reflux outlet. As shown in Figure 12f,g, Cases 6 and 7 had a similar settling velocity distribution to Cases 1-5. In Figure 12h,i, with increasing influent flow rate, the high-value area $(>0.0015 \mathrm{~m} / \mathrm{s})$ of the sludge settling velocity at the bottom of the tank constantly extended in the $x$ direction but significantly decreased in the $y$ direction.
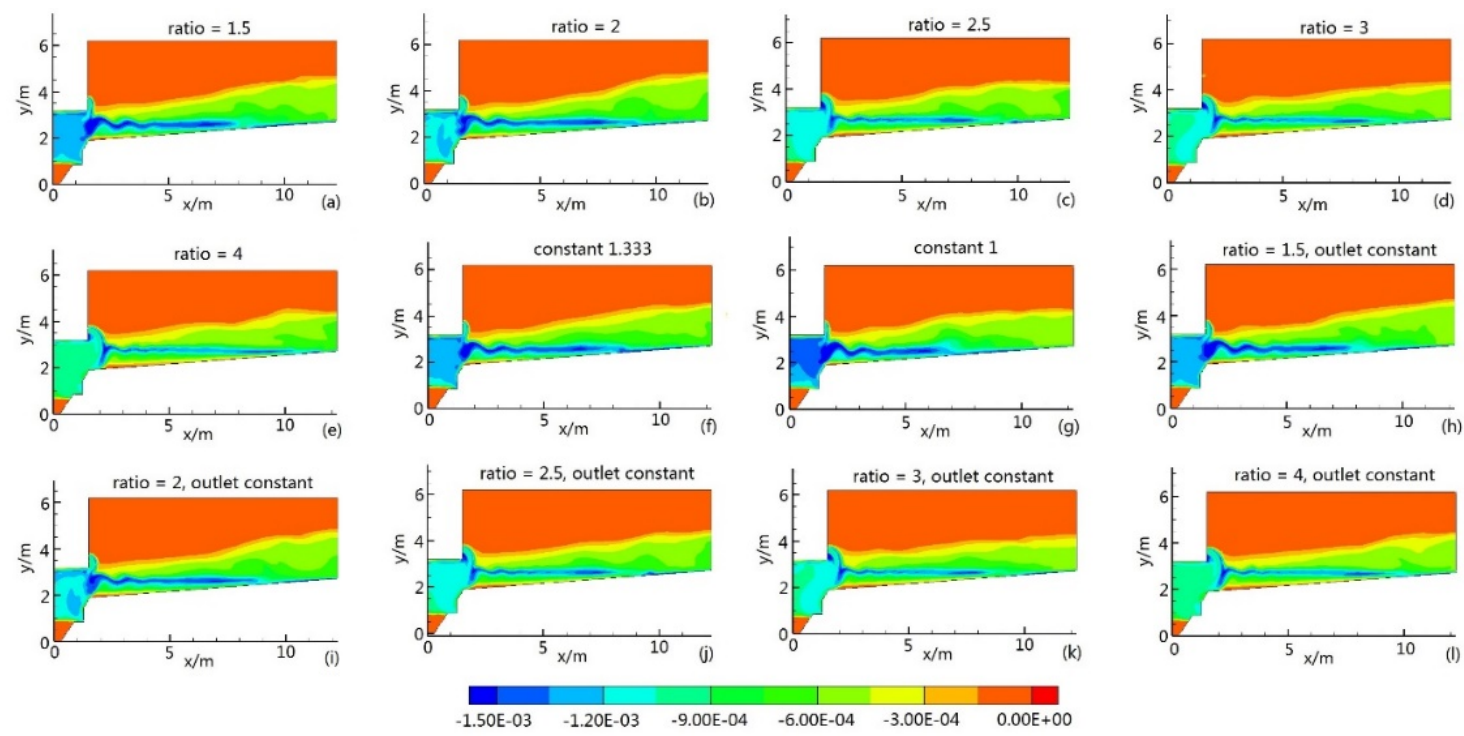

Figure 12. Settling velocity magnitude distribution under different cases: (a) Case 1; (b) Case 2; (c) Case 3; (d) Case 4; (e) Case 5; (f) Case 6; (g) Case 7; (h) Case 8; (i) Case 9; (j) Case 10; (k) Case 11; (l) Case 12.

\section{Conclusions}

In this paper, we studied the dynamic behaviors of solid-liquid two-phase flow in a tank under influent flow rate variations using a method coupling a mixture model and drift equation while considering the sludge rheological properties due to the sludge concentration. Meanwhile, a dynamic boundary method was developed to describe changes of the flow velocity with time. Moreover, validation of the inflow changes, velocity, and phase volume was given by comparing with experimental or analyzed values.

With increasing influent flow rate, the vortex structure in the upper part of the tank changed dramatically, while the vortex structures in the middle and bottom of the tank were relatively stable. 
The sludge accumulated continuously in the bottom left side of the tank, sludge hopper, and inlet; the sludge blanket thickness near the right end of the tank increased continuously; and the sludge concentration in the tank approximately linearly increased with time, with low slope. The settings of the dynamic flow rate at the reflux outlet had a limited influence on the sludge concentration, sludge distribution, mixed liquid velocity distribution, and sludge settling velocity distribution in different areas of the tank.

In actual sewage treatment processes, it is necessary to avoid too fast a flow increase with time, as it leads to a rise in the sludge blanket height and higher sludge concentration in the effluent. In addition, in order to reduce the flow velocity at the inlet, a baffle plate is set around the inlet of the tank. Multiple regulating tanks can be set up to keep the inlet flow stable.

Further studies on the modeling of wastewater treatment processes in secondary sedimentation tanks should consider the dynamic inlet sludge concentration. The biological and physical properties of the sludge also affect the settlement characteristics. Therefore, it is necessary to further study the settling velocity and rheological properties of sludge.

Author Contributions: J.S. and L.W. proposed the main framework of the paper. J.S. and L.W. mainly wrote the paper. Y.Z. and Z.G. proofread the paper.

Funding: This work was supported by the National Science and Technology Major Project (No. 2016ZX05011001), the Natural Science Basic Research Plan in Shaanxi Province of China (2019-JQ335, 2018-JQ5073), and the National Natural Science Foundation of China (No. 11572242, 41861144021, 11872295).

Conflicts of Interest: The authors declare no conflict of interest.

\section{References}

1. Ji, Z.; Mccorquodale, J.A.; Zhou, S.; Vitasovic, Z. A dynamic solids inventory model for activated sludge systems. Water Environ. Res. 1996, 68, 329-337. [CrossRef]

2. Ekama, G.A.; Barnard, J.L.; Gunthert, F.W.; Krebs, P. Secondary Settling Tank: Theory, Modelling, Design and Operation; Scientific and Technical Report No.6; IAWQ: London, UK, 1997; pp. 105-116.

3. Ekama, G.A.; Marais, P. Hydrodynamic Modelling of Secondary Settling Tanks; WRC Report No. 835/1/02 Part 1; Water Resources Group, Department of Civil Engineering, University of Cape Town: Cape Town, South Africa, 2002.

4. Skoczko, I.; Struk-Sokołowska, J.; Ofman, P. Modeling changes in the parameters of treated sewage using artificial neural networks. Annu. Set Environ. Prot. 2017, 19, 633-650.

5. Ofman, P.; Struk-Sokołowska, J. Artificial Neural Network (ANN) Approach to Modelling of Selected Nitrogen Forms Removal from Oily Wastewater in Anaerobic and Aerobic GSBR Process Phases. Water 2019, 11, 1594. [CrossRef]

6. Valle Medina, M.E.; Laurent, J. Incorporation of a compression term in a CFD model based on the mixture approach to simulate activated sludge sedimentation. Appl. Math. Model. 2020, 77, 848-860. [CrossRef]

7. Xu, G.; Yin, F.; Xu, Y.; Yu, H.Q. A force-based mechanistic model for describing activated sludge settling process. Water Res. 2017, 127, 118-126. [CrossRef] [PubMed]

8. Das, S.; Bai, H.; Wu, C.; Kao, J.H.; Barney, B.; Kidd, M.; Kuettel, M. Improving the performance of industrial clarifiers using three-dimensional computational fluid dynamics. Eng. Appl. Comp. Fluid Mech. 2016, 10, 130-144. [CrossRef]

9. Meister, M.; Winkler, D.; Rezavand, M.; Rauch, W. Integrating hydrodynamics and biokinetics in wastewater treatment modelling by using smoothed particle hydrodynamics. Comput. Chem. Eng. 2017, 99, 1-12. [CrossRef]

10. Tamayol, A.; Firoozabadi, B.; Ashjari, M.A. Hydrodynamics of secondary settling tanks and increasing their performance using baffles. J. Environ. Eng. 2009, 136, 32-39. [CrossRef]

11. Byonghi, L. Evaluation of Double Perforated Baffles Installed in Rectangular Secondary Clarifiers. Water 2017, 9, 407.

12. Saffarian, M.R.; Hamedi, M.H.; Sharms, M. Numerical simulation of a secondary clarifier in a sewage treatment plant using modified Bingham model. Can. J. Civil Eng. 2011, 38, 11-22. [CrossRef] 
13. Ramin, E.; Wagner, D.S.; Yde, L.; Binning, P.J.; Rasmussen, M.R.; Mikkelsen, P.S.; Plósza, B.G. A new settling velocity model to describe secondary sedimentation. Water Res. 2014, 66, 447-458. [CrossRef] [PubMed]

14. Patziger, M. Computational fluid dynamics investigation of shallow circular secondary settling tanks: Inlet geometry and performance indicators. Chem. Eng. Res. Des. 2016, 112, 122-131. [CrossRef]

15. Lakehal, D.; Krebs, P.; Krijgsman, J.; Rodi, W. Computing Shear Flow and Sludge Blanket in Secondary Clarifiers. J. Hydraul. Eng. 1999, 125, 253-262. [CrossRef]

16. Weiss, M.; Plósz, B.G.; Essemiani, K.; Meinhold, J. Suction-lift sludge removal and non-Newtonian flow behaviour in circular secondary clarifiers: Numerical modelling and measurements. Chem. Eng. J. 2007, 132, 241-255. [CrossRef]

17. Taebi-Harandy, A.; Schroeder, E.D. Formation of density currents in secondary clarifier. Water Res. 2000, 34, 1225-1232. [CrossRef]

18. Guo, H.; Ki, S.J.; Oh, S.; Kim, Y.M.; Wang, S.; Kim, J.H. Numerical simulation of separation process for enhancing fine particle removal in tertiary sedimentation tank mounting adjustable baffle. Chem. Eng. Sci. 2017, 158, 21-29. [CrossRef]

19. Gao, H.W.; Stenstrom, M.K. Evaluation of three turbulence models in predicting the steady state hydrodynamics of a secondary sedimentation tank. Water Res. 2018, 143, 445-456. [CrossRef]

20. Gao, H.W.; Stenstrom, M.K. Generalizing the effects of the baffling structures on the buoyancy-induced turbulence in secondary settling tanks with eleven different geometries using CFD models. Chem. Eng. Res. Des. 2019, 143, 215-225. [CrossRef]

21. Gao, H.; Stenstrom, M.K. Turbulence and interphase mass diffusion assumptions on the performance of secondary settling tanks. Water Environ. Res. 2019, 91, 101-110. [CrossRef]

22. Patziger, M.; Kainz, H.; Hunze, M.; Józsad, J. Influence of secondary settling tank performance on suspended solids mass balance in activated sludge systems. Water Res. 2012, 46, 2415-2424. [CrossRef]

23. Su, J.W.; Chai, G.L.; Wang, L.; Cao, W.D.; Gu, Z.L.; Chen, C.G.; Xu, X.Y. Pore-scale direct numerical simulation of particle transport in porous media. Chem. Eng. Sci. 2019, 199, 613-627. [CrossRef]

24. Bhusare, V.H.; Kalaga, D.V.; Dhiman, M.K.; Joshi, J.B.; Roy, S. Mixing in a Co-Current Upflow Bubble Column Reactors with and without Internals. Can. J. Chem. Eng. 2018, 96, 1957-1971. [CrossRef]

25. Dahl, C.P. Modelling of Flow Field and Settling in Secondary Settling Tanks. Ph.D. Thesis, Aalborg University, Aalborg, Denmark, 1993.

26. Rodi, W. Turbulence Models and Their Application in Hydraulics, 3rd ed.; Balkema: Rotterdam, The Netherlands, 1993.

27. Guyonvarch, E.; Ramin, E.; Kulahci, M.; Plósza, B.G. iCFD: Interpreted Computational Fluid Dynamics-Degeneration of CFD to one-dimensional advection-dispersion models using statistical experimental design-The secondary clarifier. Water Res. 2015, 83, 396-411. [CrossRef] [PubMed]

28. Eshtiaghi, N.; Markis, F.; Yap, S.D.; Baudez, J.C.; Slatter, P. Rheological characterisation of municipal sludge: A review. Water Res. 2013, 47, 5493-5510. [CrossRef]

29. Ratkovich, N.; Horn, W.; Helmus, F.P.; Rosenberger, S.; Naessens, W.; Nopensd, I.; Bentzena, T.R. Activated sludge rheology: A critical review on data collection and modelling. Water Res. 2013, 47, 463-482. [CrossRef]

30. TakÁcs, I.; Patry, G.G.; Nolasco, D. A Dynamic Model of the Clarification Thickening Process. Water Res. 1991, 25, 1263-1271. [CrossRef]

31. ValverdePérez, B.; Penkarskirodon, E.; Zhang, X.; Wágner, D.S.; Plósz, B.G. Practical parameter identifiability for an activated sludge hindered-transient-compression settling velocity model-Assessing data requirements and model structural complexity. Proc. Water Environ. Fed. 2016, 14, 5614. [CrossRef]

32. Su, J.W.; Wang, L.; Liu, Y.J. Two-Phase flow numerical simulation of secondary settling tank and influence of mixed liquor rheological properties. Tech. Water Treat. 2019, 7, 47-53. (In Chinese)

33. Su, J.W.; Wang, L.; Gu, Z.L.; Chen, J. Numerical simulation of solid/ non-Newtonian liquid two-phase flow in the secondary sedimentation tanks with different inlet flow rates. Chin. J. Appl. Mech. 2019, 05, 1018-1025. (In Chinese)

34. Brennan, D. The Numerical Simulation of Two-Phase Flows in Settling Tanks. Ph.D. Thesis, Imperial College, London, UK, 2001.

35. Imam, E. Numerical Modeling of Rectangular Clarifiers. Ph.D. Thesis, University of Windsor, Windsor, ON, Canada, 1981. 
36. Van, M.C.; Kranenburg, C. Effects of gravity currents in circular secondary clarifiers. J. Environ. Eng. 1994, 120, 943-960.

37. Kim, H.S.; Shin, M.S.; Jang, D.S.; Jung, S.H.; Jin, J.H. Study of flow characteristics in a secondary clarifier by numerical simulation and radioisotope tracer technique. Appl. Radiat. Isotopes 2005, 63, 519-526. [CrossRef] [PubMed] 